\title{
Duas importantes revistas de educação para os pesquisadores da área
}

Consuelo Ivo

Editora executiva da revista Comunicação \& Educação.

E-mail: consuelo.ivo@terra.com.br

Neste Serviço apresentamos duas importantes publicações para a área de educação. A revista Educação e Pesquisa, da Faculdade de Educação, tem 32 anos de existência. A revista Leitura: Teoria \& Prática é um periódico semestral da Associação de Leitura do Brasil e comemora em 200725 anos de circulação ininterrupta.

\section{EDUCAÇÃO E PESQUISA - HISTÓRICO}

Ao ser instituída, em 1975, cinco anos após a criação da Faculdade de Educação da USP (FEUSP), a revista foi concebida como uma publicação destinada à divulgação dos estudos e investigações dessa unidade universitária. Sob tal perspectiva, foi durante vários anos um veículo dirigido prioritariamente à divulgação da produção científica dos professores da FEUSP. Na última década, a revista passou a divulgar a produção científica da área educacional em geral, sem se restringir a temáticas específicas ou à filiação institucional dos autores. Essa mudança se expressa na nova composição de seu Conselho Editorial, que conta com pesquisadores de diversas instituições nacionais e estrangeiras, ao lado do conjunto de professores da própria faculdade.

Para entender o surgimento da revista da Faculdade de Educação, é necessário relembrar um pouco sua história. Em 1920, foi criada a Faculdade de Educação, que não chegou a funcionar. O Instituto de Educação foi instalado em 1933 e, no ano seguinte, incorporado à Universidade de São Paulo. Em 1938, o Instituto foi transformado na Seção de Pedagogia da Faculdade de Filosofia, Ciências e Letras da Universidade de São Paulo (FFCL/USP), e posteriormente no Departamento de Educação. Essa Faculdade publicava a Revista de Pedagogia, com as seguintes finalidades: tornar-se elemento de ligação entre a Faculdade e seus ex-alunos; ser órgão de informação e atualização de professores não formados pela Faculdade e de seus ex-alunos; e divulgar conhecimento educacional útil, buscando a melhoria do ensino. O primeiro número foi publicado em 1955, com vários artigos e resenhas de livros, e o último, número 23, em 1967. 
No mesmo prédio do Departamento de Pedagogia - FFCL/USP, na Cidade Universitária, funcionava o Centro Regional de Pesquisas Educacionais Prof. Queiroz Filho - CRPE/SP, mantido pelo INEP, que publicava a revista Pesquisa e Planejamento, para divulgar as atividades e pesquisas realizadas pelo órgão. Ela foi publicada de 1957 a 1975 (número 17). O CRPE/SP foi extinto em 1973 e os bens passaram para a Faculdade de Educação.

Em 16 de dezembro de 1969, foi criada a Faculdade de Educação da USP, que em 1975 publicou o primeiro número da Revista da Faculdade de Educação. Em 1987, no volume 13, seu Conselho Editorial apareceu pela primeira vez. Esse Conselho era composto de professores da FEUSP, de outras unidades da USP e de especialistas da área pertencentes a instituições várias.

A apresentação visual da revista sofreu três modificações substanciais. A primeira surgiu no volume 17, em 1991, com uma capa elaborada pelo Serviço de Recursos Audiovisuais da Faculdade de Educação. A segunda mudança deu-se em 1995, com o volume 21, em que a capa foi idealizada pelo artista plástico francês Zaveb Pare, que a produziu graciosamente para a Faculdade.

Em 11 de março de 1999, a nova Comissão de Publicações submeteu à apreciação da Congregação da FEUSP a terceira modificação: o projeto de reestruturação da Revista da Faculdade de Educação, que previa a mudança do seu título, entre outras alterações a serem introduzidas. O objetivo da proposta era torná-la mais atualizada aos padrões vigentes das publicações científicas, visando a uma melhoria na difusão dos conhecimentos na área da Educação e, conseqüentemente, a um aumento de intercâmbio entre os especialistas nacionais e estrangeiros.

Além disso, objetivava-se, também, a médio prazo, obter sua indexação a Índices e Abstracts nacionais e internacionais. Assim, após uma consulta ao corpo docente e discente da FEUSP para escolha de um novo título para a revista, dentre os vários apresentados, Educação e Pesquisa foi o vencedor. A partir do volume 25, número 2, introduziu-se a seção Em Foco, para levar ao leitor temas específicos na área de educação.

Essa mesma equipe providenciou algumas mudanças necessárias em relação aos aspectos técnicos da revista, como ISSN, legenda bibliográfica, referências, resumos, descritores, instrução aos autores etc.

Com todas essas alterações, obteve-se financiamento do CNPq, da Comissão de Credenciamento da USP (SIBI/USP), da CAPES e da FAPESP para a produção da revista. A avaliação na Tabela Qualis/CAPES como Internacional "A", a sua inserção no projeto SciELO (Scientific Electronic Library Online) e o aumento do número de artigos enviados para publicação levaram a equipe editorial a alterar a periodicidade de semestral para quadrimestral.

Foi realizado um convite a universidades que tivessem interesse em assinar a revista, a qual conta hoje com cerca de 280 assinantes, entre pessoas jurídicas e físicas. Também passou a ser comercializada diretamente na FEUSP e, por consignação, com editoras interessadas.

O Conselho Editorial é constituído de pesquisadores de comprovada competência no campo da educação, vinculados às principais universidades brasileiras 
Duas importantes revistas de educação para os pesquisadores da área • Consuelo Ivo

e estrangeiras. Integram o conselho a profa. dra. Lucia Bruno (editora), profa. dra. Teresa Rego, profa. dra. Marta Khol, profa dra. Isabel de Almeida, prof. dr. Claudemir Belintane e prof. dr. Pedro Jacobi.

A partir de 2005, foi decidido pela Comissão Editorial que alguns artigos seriam publicados on-line pela SciELO, em inglês.

Abaixo, os serviços de busca:

- <http://www2.fe.usp.br/estrutura/>.

- <http://www.scielo.br>.

- <http://www.redalyc.com>.

E os indexadores:

- BBE (Bibliografia Brasileira de Educação) - Brasil, INEP.

- Edubase (FE/UNICAMP).

- Iresie (Índice de Revistas de Educación Superior e Investigación Educativa) - México.

- Clase (Citas latinoamericanas en Ciencias Sociales y Humanidades) - México.

- Psicodoc (Colegio Oficial de Psicólogos de Madrid) - Espanha.

- Latindex (Sistema Regional de Información en Linea para Revistas Científicas de América Latina, en Caribe, España y Portugal) - México.

- Sociological Abstract (www.csa.com/factsheets/supplements/sociossl.php) - EUA.

- ERA (Educational Research Abstracts - www.tandf.co.uk/era/) - Inglaterra.

- DOAJ (Directory of Open Access Journals) - Suécia.

- AERA SIG (Communication of Research - <http://aera-cr.asu.edu/) - EUA.

Serviço: Revista Educação e Pesquisa - FEUSP. Endereço para correspondência: Faculdade de Educação da Universidade de São Paulo - Comissão Editorial: Av. da Universidade, 308 - sala 27 - bloco B - CEP: 05508-040 - São Paulo-SP - Brasil. Tel./fax: (11) 3091-3520. E-mail: revedu@edu.usp.br. Site: <http://www2. fe.usp.br/estrutura/>.

\section{REVISTA LEITURA: TEORIA \& PRÁTICA}

A revista Leitura: Teoria \& Prática é um periódico semestral da Associação de Leitura do Brasil, publicada atualmente pela Editora Global. Neste ano, comemora 25 anos de circulação ininterrupta e tem-se construído como espaço de informação, reflexão e divulgação de conceitos, representações, práticas, atitudes sobre leitura e escritura, especialmente em sua interface com a escola, cultura e educação.

Criado no início dos anos 1980, esse periódico foi marcado fortemente pelo cenário histórico de mobilização civil, e desde então tem como desafio a luta pela democratização da leitura, posicionando-se contra a desigualdade e exclusão cultural da grande maioria dos brasileiros.

Veicula em suas seções Estudos, Artigos, Imagens de Leitura, Textos Literários, Resenhas, entre outras, a contribuição de intelectuais e artistas de 
reconhecido mérito e de pesquisadores que iniciam a reflexão na área da leitura, de diferentes regiões do País. Em cada número, é possível também contar com a colaboração de autores estrangeiros, principalmente da América Latina, ampliando a discussão sobre a temática.

O número 48, lançado em julho de 2007, traz um novo projeto editorial idealizado pela diretoria da ALB, que assume o biênio 2007-2008. Reconhece que as práticas de leitura e de escritura ocorrem em espaços diversos, numa multiplicidade de materiais escritos com seus suportes de textos e inúmeras combinações e estratégias, a exigir reflexões cada vez mais interdisciplinares e complexas.

Seu Conselho Editorial, presidido pela profa. dra. Norma Sandra de Almeida Ferreira, chefe do Departamento de Educação, Conhecimento, Linguagem e Arte da Faculdade de Educação/Unicamp, é constituído com os professores Lílian Lopes Martin da Silva, Milton José de Almeida, Ezequiel Theodoro da Silva (FE/Unicamp), João Wanderley Geraldi, Raquel Salek Fiad, Márcia Abreu (IEL/Unicamp), Maria do Rosário Mortatti (Unesp) e Luiz Percival Leme de Brito (UNISO). A revista conta ainda com um Conselho Editorial Externo, formado por pesquisadores de diferentes instituições brasileiras.

Os interessados em contribuir para a ampliação da discussão sobre educação, leitura e cultura escrita em seus contextos atuais e de outros tempos e lugares, podem acessar o site <http://www.alb.com.br $>$ e inteirar-se das normas editoriais para publicação na revista Leitura: Teoria \& Prática.

Serviço: Revista Leitura: Teoria \& Prática. Faculdade de Educação, Anexo II - Unicamp. Caixa Postal 6.117 - CEP: 13.083-970 - Campinas-SP - Brasil. Tel./fax: (19) 3289.41-66. E-mail: secretaria@alb.com.br. Site: <http://www.alb. com.br>.

Resumo: A revista Educação e Pesquisa é uma publicação quadrimestral da Faculdade de Educação da Universidade de São Paulo - FEUSP, desde 1975. Divulga artigos inéditos na área de educação, em especial resultados de pesquisas de caráter teórico ou empírico, revisões da literatura de pesquisa educacional e reflexões críticas sobre experiências pedagógicas. A revista Leitura: Teoria \& Prática é um periódico semestral da Associação de Leitura do Brasil (ABL). Em 2007 comemora 25 anos de circulação ininterrupta. A revista tem-se construído como espaço de informação, reflexão e divulgação de conceitos, representações, práticas, atitudes sobre leitura e escritura, especialmente em sua interface com a escola, cultura, educação.

Palavras-chave: publicação, educação, pesquisa, Feusp, ALB.
Abstract: The journal Educação e Pesquisa is a triennial publication of the Universidade de São Paulo College of Education - FEUSP - since 1975. It divulges inedited articles, especially results of empiric and theoretical researches, educational research literature reviews and critical reflections on pedagogic experiences. The journal Leitura: Teoria \& Prática is the Associação de Leitura do Brasil (Brazilian Reading Association) - ABL - biannual periodical. In 2007, it commemorated 25 years of uninterrupted circulation. The journal has been built as a space of information, reflection and disclosure of concepts, representations, practices, positioning on reading and writing, especially in its interface with school, culture and education.

Keywords: publication, education, research, Feusp, ALB. 